\title{
EVALUACIÓN AMBIENTAL ESTRATÉGICA Y PLANIFICACIÓN TERRITORIAL. ANÁLISIS ANTE SU REGULACIÓN LEGAL, REGLAMENTARIA Y LA JURISPRUDENCIA ADMINISTRATIVA
}

\section{STRATEGIC ENVIRONMENTAL ASSESSMENT AND THE TERRITORIAL PLANNING. ANALYSIS OF LEGAL REGULATION, REGULATORY AND ADMINISTRATIVE JURISPRUDENCE}

\section{Eduardo Cordero QuinzaCara* Iris Vargas Delgado**}

\begin{abstract}
RESUMEN: Este trabajo tiene por finalidad analizar los antecedentes y fundamentos de la Evaluación Ambiental Estratégica (EAE) en nuestro ordenamiento y su aplicación a los instrumentos de planificación territorial a partir de su regulación legal y reglamentaria reciente, así como de la jurisprudencia administrativa emanada de la Contraloría General de la República. Los autores sostienen que la EAE constituye un instrumento necesario e idóneo, cuyas dificultades en su implementación no se deben al marco jurídico vigente.
\end{abstract}

Palabras clave: Evaluación Ambiental Estratégica, Planificación Territorial, Jurisprudencia Administrativa.

\begin{abstract}
This paper reviews the background and purpose of the Strategic Environmental Assessment (SEA) in our legal system and its application to urban planning, from its recent legal and statutory regulations, as well as administrative interpretation of the Contraloría General de la República. The authors argue that the SEA is a necessary and appropriate instrument, and the difficulties in the implementation can't be attributed to the legal framework currently.
\end{abstract}

Key words: Strategic Environmental Assessment, Urban Planning, Administrative Jurisprudence.

\footnotetext{
Abogado, Doctor en Derecho, Profesor de Derecho Administrativo de la Pontificia Universidad Católica de Valparaíso, Chile. Dirección Postal: Brasil No 2950, Valparaíso. Correo electrónico: eduardo.cordero@ucv.cl Este trabajo es parte de una investigación financiada por FONDECYT referida al proyecto «La revisión de las bases dogmáticas del derecho urbanístico chileno. Propiedad, urbanismo y regulación de las actividades económicas» No 1130956.

" Abogada, Magíster en Derecho Público por la Pontificia Universidad Católica de Chile, Doctora en Derecho por la Universidad Complutense de Madrid. Dirección Postal: Brasil No 2950, Valparaíso. Correo electrónico: ivargasd@hotmail.com
} 


\section{INTRODUCCIÓN}

Los cambios experimentados en nuestra legislación ambiental en las últimas décadas han sido vertiginosos, dando cuenta de una mayor compresión, conocimiento y experiencia para enfrentar los problemas que nos plantean los procesos de degradación del medio ambiente. Un hito relevante lo ha marcado la entrada en vigencia en el año 1994 de la Ley No 19.300, sobre Bases Generales del Medio Ambiente, que en una visión sistémica del problema ambiental y con las primeras técnicas de gestión ambiental, comienza a consolidarse a partir del año 1997 con la aplicación del Sistema de Evaluación de Impacto Ambiental (SEIA). Tampoco cabe ninguna duda que la dictación de la Ley No 20.417, de 26 de enero de 2010, sobre nueva Institucionalidad Ambiental, mejoró la forma en que las entidades administrativas debían organizarse para ejercer sus competencias, delimitando con claridad sus funciones, e introduciendo una mejora sustantiva en la gestión ambiental con nuevos instrumentos no previstos en la legislación original, como ha ocurrido con la Evaluación Ambiental Estratégica (EAE).

Habiendo transcurrido más de cinco años de la vigencia de la EAE en nuestro sistema, el presente trabajo tiene por finalidad estudiar su aplicación en el ámbito de la planificación territorial. Así, daremos cuenta del concepto de EAE (1), para luego analizar la definición legal, la forma como se ha regulado su procedencia, las autoridades que deben intervenir y las etapas que comprende (2). Esto nos permitirá sentar las bases para el estudio del procedimiento que deben seguir los instrumentos de planificación territorial para su EAE, dando cuenta de los problemas que se presentaron ante la ausencia de regulación reglamentaria y los aspectos que resuelve el actual Reglamento para la EAE (3), así como la determinación de los actos de incidencia territorial que están sometidos a dicha evaluación (4), para analizarlos criterios que ha establecido la jurisprudencia administrativa en esta materia (5).

La hipótesis que pretendemos demostrar es que la EAE constituye un instrumento necesario e idóneo para adoptar medidas preventivas al nivel de las más altas decisiones de las autoridades gubernamentales, pero que ha planteado serias dificultadas en su aplicación. A nuestro parecer estas no se pueden imputar al marco jurídico vigente, sino a la forma como se ha implementado y a los problemas propios de un procedimiento administrativo complejo que hace más lenta la adopción de decisiones públicas.

\section{CONCEPTO DE EVALUACIÓN AMBIENTAL ESTRATÉGICA (EAE)}

La EAE no es un instrumento de creación original. Sus antecedentes se pueden encontrar a fines de la década de los sesenta del siglo pasado en los Estados Unidos y en los países que actualmente forman la Unión Europea. El punto de partida lo constituye la primera Acta Nacional de Política Ambiental (National Environmental Policy Act, NEPA) de Estados Unidos dictada en el año 1969, la cual exigió la realización de informes sobre las consecuencias ambientales de acciones federales o de actividades que requirieran permisos o autorizaciones federales. Esta iniciativa fue seguida posteriormente por Canadá (Federal Environmental Assesment Review Process de 1973); Australia (Commonwealth Government's En- 
vironmental Protection Acta de 1974); Alemania (Principles for Assessing the Environmental Compatibility of Public Measure of the Fereration de 1975) y Francia (Law on the Protection of the Natural Environment de 1976) ${ }^{1}$. En el caso de la Unión Europea el punto de partida lo marcan las Directrices del Consejo Europeo (85/337/EEC), habiéndose publicado a la fecha diversos proyectos de directrices recogidos por los estados miembros ${ }^{2}$. Por lo tanto, la modificación realizada en Chile en el año 2010 vino a incorporar un instrumento que ya reconocía cierta tradición, experiencia y reflexión en el derecho comparado.

Ahora bien, la definición de EAE más extendida es la entregada por THERIVEL, según la cual la EAE sería un proceso formalizado, sistemático y global para evaluar los impactos ambientales de una política, plan o programa, así como sus alternativas, incluida la preparación de un informe escrito sobre los resultados de esa evaluación y el uso de los mismos para la adopción de decisiones públicas respecto de las cuales se debe rendir cuenta ${ }^{3}$. Por su parte, y desde una perspectiva más jurídica, JACQUENOD DE ZsöGON la define como el procedimiento administrativo sistemático y reglado mediante el cual se pueden identificar, valorar y comunicar las previsibles consecuencias ambientales que determinadas políticas, planes o programas podrían provocar ${ }^{4}$.

En la doctrina chilena también se ha seguido una línea similar. Así, Guerrero Valle sostiene que se trata de un procedimiento administrativo orientado a apoyar la toma de decisiones de naturaleza estratégica, traducidas en políticas, planes e instrumentos de ordenamiento territorial, constituyéndose de esa forma, en un proceso de identificación, análisis y evaluación previa de impactos de naturaleza estratégica 5 .

Por nuestra parte, coincidimos con VERHEEM y TONK en el sentido de que a pesar de utilizarse diferentes definiciones, la doctrina está de acuerdo en un concepto general de EAE: se trata de un proceso estructurado y proactivo para fortalecer el papel de las cuestiones ambientales en la toma de decisiones estratégicas. Las diferencias podrían encontrarse en los distintos enfoques, como por ejemplo en su apertura (con o sin la participación del público en general), su ámbito de aplicación (con o sin la descripción obligatoria de alternativas) o su intensidad y duración (desde un día hasta varios años) ${ }^{6}$.

Por otra parte, si bien la EAE es definida como un procedimiento, aquello no la priva de la condición esencial, esto es, ser un instrumento de gestión ambiental ${ }^{7}$. En este sentido, debemos tener presente que tal evaluación se inserta dentro del diseño o preparación de la respectiva política, plan o programa de carácter normativo general, que a su vez, suele tener un procedimiento propio.

\footnotetext{
1 FisCHER (2007) pp. 1-3.

2 Dalal-Claytony Sadler (2005) pp. 44-52, y Wood y Dejeddour (1992) pp. 3-22.

3 Therivel et al. (1994); también en Therivel y Paridario (2002) p. 4. Asimismo vid. Clark (1997) pp. 1-22, en particular p. 4.

4 JACQUeNOD DE ZsÖGON (2001) p.101.

5 Guerrero Valle (2012) pp. 104-105.

6 Verheem y Tonk (2000) pp. 177-182.

7 VAREla del Solar (2012) pp. 302-303. Al respecto, recuérdese que el propio legislador ha incorporado la normativa de la EAE en el Título II de la Ley No 19.300, relativo a los instrumentos de gestión ambiental, párrafo $1^{\circ}$ bis.
} 


\section{RECONOCIMIENTO DE LA INSTITUCIÓN EN EL DERECHO CHILENO}

\subsection{Definición LeGAL}

Tal como hemos señalado, la Ley No 20.417 incorpora en nuestra legislación la EAE. Con ello separa con cierta claridad el objetivo de este instrumento con el SEIA, vinculado a proyectos específicos y no a decisiones de carácter estratégico. Además, resuelve las críticas que se planteaban en su oportunidad respecto de sentido y justificación de la evaluación de los instrumentos de planificación territorial bajo el SEIA, cuyo objeto es claramente diverso.

Por su parte, también el legislador adoptó la decisión de darnos una definición de este instrumento, señalando que la EAE es "el procedimiento realizado por el Ministerio sectorial respectivo, para que se incorporen las consideraciones ambientales del desarrollo sustentable, al proceso de formulación de las políticas y planes de carácter normativo general, que tengan impacto sobre el medio ambiente o la sustentabilidad, de manera que ellas sean integradas en la dictación de la respectiva política y plan, y sus modificaciones sustanciales". En general, este concepto entiende que es un procedimiento cuya naturaleza es de carácter administrativo. Bajo dicho presupuesto los principios que lo orientan resultan de la confluencia entre la legislación general administrativa y la legislación ambiental, como sucede con la coordinación, participación ciudadana, publicidad y transparencia, entre otros ${ }^{8}$.

\subsection{Procedencia de la EAE}

La EAE será obligatoria en los casos previstos directamente por la ley y podrá ser aplicable también a otras situaciones, conforme a lo que disponga el Presidente de la República'. Así, por la vía reglamentaria es posible ampliar su aplicación, otorgando un mayor grado de discrecionalidad a la autoridad, aunque sujeta a los límites que impone el propio legislador (carácter normativo general), con lo cual se da cierta flexibilidad y permite adaptarse a las nuevas necesidades de evaluación ambiental ${ }^{10}$.

Ahora bien, un primer grupo está constituido por aquellas políticas y planes de carácter normativo general respecto de las cuales siempre procederá la EAE, incluyendo sus modificaciones sustanciales. Se trata en este caso de diversos instrumentos de incidencia territorial y que se enumeran por la ley, a saber: los planes regionales de ordenamiento territorial o PROT, planes reguladores intercomunales, planes reguladores comunales y planes seccionales, los planes regionales de desarrollo urbano, las zonificaciones del borde costero y del territorio marítimo y el manejo de cuencas. Asimismo, procederá la evaluación en caso de que tales instrumentos sean reemplazados o sistematizados ${ }^{11}$. Además, dentro

\footnotetext{
8 Sobre estos principios vid. Guerrero Valle (2012) pp.105-106, y Carrasco Quiroga (2012) pp. 426-428.

9 Artículo $7^{\circ}$ bis de la Ley $\mathrm{N}^{\circ} 19.300$.

10 Carrasco Quiroga (2012) p. 423. Este autor sostiene que se estaría "deslegalizando un asunto que requiere mayores precisiones legales”. En todo caso, el Tribunal Constitucional ha aceptado esta técnica legislativa. Cfr. Cordero (2009) pp. 409-440.

11 El Reglamento de la EAE, define en su artículo $4^{\circ}$, letra i) lo que debe entenderse por instrumentos de ordenamiento territorial para los efectos de la EAE, incluyendo aquellos instrumentos enumerados por el artículo $7^{\circ}$ bis de la Ley $\mathrm{N}^{\circ} 19.300$.
} 
de este grupo, debemos distinguir entre aquellos que cuentan con regulación legal, como sucede con todos los instrumentos de planificación territorial previstos en la Ley General de Urbanismo y Construcciones (LGUC) ${ }^{12}$, respecto de aquellos que carecen de dicha regulación y que solo son previstos por el artículo $7^{\circ}$ bis como instrumentos futuros, como el PROT y los planes de manejo de cuencas.

En un segundo grupo se encuentran aquellas políticas y planes de carácter normativo general, y sus modificaciones sustanciales, que tengan impacto sobre el medio ambiente o la sustentabilidad, que hayan sido incluidos al efecto por el Presidente de la República, a proposición del Consejo de Ministros. Al respecto, parece necesario insistir que cualquier política o plan que se incluya debe siempre de carácter normativo general, lo cual impide imponer este instrumento respecto de actos que no tienen esta naturaleza, aun cuando la propia autoridad decida llevarlo de forma voluntaria ${ }^{13}$.

En este caso resulta de interés determinar qué debe entenderse por "políticas y planes de carácter normativo general" ${ }^{14}$. Si seguimos el sentido natural y obvio de estos términos se puede decir que una "política de carácter normativo general" sería aquella que contemple las orientaciones o directrices que regirán la actuación de una entidad pública en un asunto o campo determinado, la que deberá ser aprobada mediante un instrumento jurídico con fuerza obligatoria de carácter general ${ }^{15}$. A su vez, "plan de carácter normativo general" correspondería al conjunto de pasos o etapas ordenadas anticipada y sistemáticamente para dirigir y encauzar la actuación de una entidad pública en orden a un objetivo o fin determinado, la que igualmente deberá ser aprobada mediante un instrumento jurídico con fuerza obligatoria de carácter general ${ }^{16}$. Así también lo ha entendido la Contraloría al señalar que no puede considerarse una política o plan de carácter normativo general un acto administrativo que regula una situación particular y concreta ${ }^{17}$.

En el mismo sentido se debe determinar el alcance de la expresión "modificación sustancial". Si estamos al su sentido natural, debemos entender que ha de tratarse de un cambio del plan o política sustancioso, esto es, debe referirse a aspectos esenciales o relevantes ${ }^{18}$. Sin embargo, aquello no nos aporta un criterio preciso para resolver la cuestión. Por su parte, el Reglamento solo aborda el problema respecto de los instrumentos de orde-

\footnotetext{
12 DFL N 458, de 1976, del Ministerio de Vivienda y Urbanismo.

13 Vid. Dictamen $N^{\circ}$ 73.497, de 2012. Por otra parte, los proyectos de reglamentos consideraron la posibilidad de un "sometimiento voluntario" a la EAE, lo que fue finalmente eliminado en el reglamento vigente.

14 La Directiva 2001/42/CE, del Parlamento Europeo y del Consejo de 27 de junio de 2001, relativa a la evaluación de los efectos de determinados planes y programas en el medio ambiente, al definir en su artículo $2^{\circ}$, letra a), los planes y programas que deben evaluarse, hace referencia a que estos pueden emanar de autoridades de diverso nivel (nacional, regional o local), ser adoptados mediante un procedimiento legislativo o ser exigidos por disposiciones legales, reglamentarias o administrativas; agregando en su artículo $3^{\circ}$ los sectores en los cuales la evaluación ambiental estratégica de los planes y programas es obligatoria.

15 Sobre los términos política, plan, normativo y general vid. Real Academia Española de la Lengua (2012). También Quijada (1994).

16 En similares términos vid. JiMÉnEZ Bueso (2014).

17 Dictamen No 73.497, de 2012.

18 Sobre los términos modificación, modificar y sustancial, vid. Real ACAdEMia EsPañola de la LenGUa (2012).
} 
namiento territorial ${ }^{19}$, sin establecer criterios generales que permitan orientar a los operadores jurídicos. A su vez, los pronunciamientos de Contraloría en esta materia solo se han limitado a los instrumentos de planificación territorial.

En nuestra opinión, no cabe duda que el término "modificación sustancial" constituye un concepto jurídico que solo se puede hacer operativo a partir de ciertos criterios orientadores teniendo presente los elementos esenciales de una política pública o plan. Por su parte, la definición de política pública y sus elementos es una cuestión que no es fácil de resolver considerando las distintas perspectivas desde la cual puede ser objeto de estudio (la administración, la sociología, la ciencia política, la economía, etc.). En todo caso, en general existe cierto consenso en entender que una política pública supone la identificación de una determinada realidad como un problema que debe ser resuelto o satisfecho por las autoridades de gobierno, para lo cual asumen ciertos objetivos o fines destinados a cambiarla a partir de determinados instrumentos o medios, con la asignación de los correspondientes recursos ${ }^{20}$. Por lo tanto, los elementos básicos o esenciales de una política pública serían: a) los problemas o necesidades que se han identificado, así como el diagnóstico de las mismas; b) los objetivos o fines planteados por la autoridad; c) los instrumentos o medios para enfrentarlos, y d) los recursos asignados. Así, cualquier cambio o reforma de algunos de estos elementos debiese ser considerada como una modificación sustancial que requiere ser aprobada previa EAE. Por otra parte, el plan es considerado en algunos casos como sinónimo de política pública, mientras que para otros sería un instrumento que permite concretar los objetivos y líneas de acción contenidos en una política, mediante la definición de los mismos, la forma de ejecución, los plazos, seguimiento y evaluación ${ }^{21}$. En este caso los cambios en estos elementos también podrían ser considerados como una modificación sustancial.

\subsection{ETAPAS DE LA EAE}

En cuanto a las etapas que comprende la EAE, es muy interesante el análisis que realiza Brian D. CLARK al indicarnos que en primer término se debe tener una visión preliminar para establecer si se requiere o no de EAE (screening), para luego identificar los problemas y alternativas claves que deben ser abordados en la evaluación desde la perspectiva ambiental (scoping). Acto seguido, se debe levantar la información básica para describir el medio ambiente existente (línea de base) y que permite determinar los cambios que se podrían presentar en el caso de que se implemente. Esto permitirá determinar los impactos ambientales considerando su magnitud y forma, para luego hacer una evaluación de los mismos. Con ello, se elabora un informe destinado a la autoridad que debe adoptar la decisión, así como a la ciudadanía que participará en el proceso. Luego dicho informe deberá ser objeto de una revisión por un órgano independiente, terminando con la adopción de la decisión y su posterior monitoreo ${ }^{22}$.

\footnotetext{
19 Artículo 31 del Reglamento de EAE.

20 En este sentido se puede consultar el trabajo hecho por la SubSecretaría de Desarrollo Regional (2009)

p. 14, así como el trabajo de MaY (2003) pp. 223-224.

21 Jiménez Bueso (2014).

22 Clark (1997) pp. 4-6.
} 
El artículo $7^{\circ}$ bis de la Ley $N^{\circ} 19.300$ considera en el procedimiento de la EAE dos etapas bien delimitadas: la etapa de diseño y la etapa de aprobación.

\section{A) Etapa de diseño}

En la etapa de diseño, la autoridad "debe considerar los objetivos y efectos ambientales del instrumento, así como los criterios de desarrollo sustentable de los mismos"23. Los demás aspectos básicos a considerar están contenidos en el actual Reglamento para la EAE, que distingue entre inicio del procedimiento, análisis de inicio, difusión del inicio, participación ciudadana, informes de los órganos administrativos participantes y reuniones o sesiones de trabajo (artículos 14 a 19).

Deben participar en esta etapa, junto con la entidad que elabora la política, plan o programa, los demás organismos de la Administración del Estado que estén vinculados a la materia, con el fin de garantizar una actuación coordinada de las entidades públicas en los proyectos afectados por el instrumento en preparación ${ }^{24}$. Tratándose de la EAE obligatoria, siempre se deben considerar los instrumentos relacionados con la capacidad vial elaborados por la autoridad competente.

Por su parte, y desde un punto de vista sustantivo, la etapa de diseño comprenderá -conforme lo expuesto anteriormente- la determinación si procede o no la EAE, la identificación de los problemas y alternativas que deben ser evaluadas, el levantamiento de la línea de base, la determinación de los impactos ambientales, la valoración de los mismos y la elaboración de un informe que deberá ser acompañado al anteproyecto de política, plan o programa.

\section{B) Etapa de aprobación}

Esta etapa se inicia con el anteproyecto, continúa con el informe ambiental el cual debe remitirse al Ministerio del Medio Ambiente para sus observaciones, sigue con la consulta pública y culmina con la resolución de término ${ }^{25}$.

Tanto el anteproyecto como el informe ambiental debe ser enviados al Ministerio. En este caso el Reglamento establece que este informe es el documento que da cuenta de la aplicación de la EAE, explicando la manera en que se abordaron los antecedentes que indica y cómo se incorporaron las consideraciones ambientales en la toma de decisión cuyo resultado es el anteproyecto de la política, plan o instrumento de ordenamiento territorial. $\mathrm{Al}$ efecto, hace una relación detallada de estos antecedentes, en donde debe haber una descripción pormenorizada del acto que se evalúa y una serie de consideraciones ambientales, como es la identificación y descripción de sus objetivos ambientales, los criterios de desarrollo sustentable considerados en su diseño, identificación y justificación de los factores críticos para la decisión, y especialmente un diagnóstico ambiental estratégico, que incluye una serie de elementos que ya hemos esbozados: descripción analítica y prospectiva del sistema territorial; descripción y explicación de los problemas ambientales existentes; la

\footnotetext{
23 Artículo $7^{\circ}$ bis de la Ley $\mathrm{N}^{\circ} 19.300$.

24 Artículos 10, 11, 19, 21 del Reglamento para la EAE.

25 Artículos 21 y ss. del Reglamento para la EAE.
} 
identificación de actores claves del territorio; la identificación de potenciales conflictos socioambientales ${ }^{26}$. En todo caso muchos de estos requisitos y condiciones son los que se han ido implementado a partir del año 2010, y que el Reglamento se ha encargado de formalizar. Además, también la envergadura de aquellos explica el carácter más complejo que han adquirido los procedimientos para adoptar estas decisiones estratégicas y la demora que se ha podido constatar en su aprobación, particularmente respecto de la planificación territorial.

Una vez que se han recibido estas observaciones, el anteproyecto debe someterse a consulta pública por el organismo responsable de la elaboración. La forma en que debe realizarse dicha consulta pública está regulada de forma pormenorizada en el Reglamento ${ }^{27}$. En cualquier caso, dicha participación ciudadana debe ser contemplada en la resolución definitiva, la que deberá indicar la consulta pública realizada y la forma en que ella ha sido considerada, como se señalará más adelante.

La ley ha estimado de suma importancia tanto la publicidad de la implementación de la política, plan o programa a evaluar como de su reformulación posterior, entregando al reglamento la regulación de la forma en que deberá hacerse tal publicidad, debiendo considerar una difusión masiva, completa y didáctica hacia los afectados y la comunidad en general, tanto de los contenidos, alcances y efectos de la política o plan o de su reformulación, según el caso.

Esta etapa de aprobación culmina con una resolución del órgano responsable, la que deberá cumplir con las exigencias que se señalan a continuación.

\section{C) Contenido de la Resolución de EAE}

La resolución de término del proceso la EAE dará cuenta de que se hayan cumplido con las etapas y requisitos que se exigen para esta evaluación, desde la etapa de diseño a la de aprobación, incluyendo la participación de otros organismos estatales, la consulta pública realizada así como la forma en que ha sido considerada, entre otros aspectos.

Asimismo, dicha resolución incluirá el contenido del informe ambiental, las respectivas consideraciones ambientales y de desarrollo sustentable que debe incorporar la política o plan para su dictación, los criterios e indicadores de seguimiento destinados a controlar la eficacia del plan o política y los criterios e indicadores de rediseño que se deberán considerar para la reformulación de dicho plan o política en el mediano o largo plazo ${ }^{28}$.

\section{D) Coordinación con el SEIA}

Es importante detenerse brevemente en analizar la estrecha relación existente entre la EAE y el SEIA, puesto que ambos instrumentos, si bien con finalidades diversas, han sido concebidos con el carácter de complementarios. En efecto, la EAE está destinado a la aprobación de planes o políticas de carácter general, por lo que informa y condiciona la evalua-

\footnotetext{
26 Artículos 21 y ss. del Reglamento para la EAE.

27 Véanse Artículos 24 y 25 del Reglamento para la EAE.

28 Artículo $7^{\circ}$ quáter de la Ley $\mathrm{N}^{\circ}$ 19.300. Esta materia se desarrolla en el artículo 26 del Reglamento.
} 
ción de proyectos específicos que deban evaluarse mediante el SEIA ${ }^{29}$. Esta utilidad que la EAE presta al SEIA fue valorada positivamente durante la discusión legislativa, ya que permitiría solucionar "varios problemas al contar con un marco general en el cual se puedan analizar los proyectos" que luego deberán ingresar al SEIA, problemas que se presentarían especialmente cuando dichos proyectos "se analizan de manera aislada de la EAE y de las dimensiones territoriales de impactos sinérgicos”, agregándose que de no existir este tipo de evaluación "se tendrá una carga excesiva sobre el SEIA"30.

En efecto, la EAE permite discutir desde el momento del diseño y elaboración de la planificación general e influir desde allí, en las decisiones relativas a los temas de mayor impacto en el medio ambiente, como los asociados a la matriz energética nacional, la planificación territorial o el uso y manejo de cuencas, entre otros, lo que permitirá, una vez evaluada estratégicamente, revisar proyecto a proyecto a través del SEIA, los impactos sinérgicos de los mismos a la luz de la política o plan aprobados previamente ${ }^{31}$. Todo ello, permitirá superar el principal problema de la evaluación de proyectos, "cual es que todo proyecto se evalúa individualmente, solo en su mérito, sin determinar sus efectos agregados ni las sinergias que puede generar" 32 .

De este modo, los proyectos o actividades sometidos al SEIA deben considerar siempre las políticas y planes evaluados estratégicamente, como lo dispone el inciso cuarto del artículo $8^{\circ}$ de la Ley $\mathrm{N}^{\circ}$ 19.300, introducido por la citada Ley $\mathrm{N}^{\circ}$ 20.417, de 2010. Para tal efecto, el proponente del proyecto o actividad que debe someterse al SEIA tendrá que identificar las políticas y planes evaluados estratégicamente que sean atingentes, la compatibilidad del proyecto o actividad con el uso del territorio y los objetivos ambientales de tales políticas y planes. La coordinación de competencias al respecto corresponde al Servicio de Evaluación Ambiental, para los efectos de obtener los permisos o pronunciamientos relativos a la $\mathrm{EAE}^{33}$.

En esta relación resulta muy relevante determinar si un determinado proyecto se va a desarrollar en un ámbito espacial sujeto a alguna política, plan o instrumento de planificación territorial evaluado estratégicamente. En el caso que aquellos existan, no se justifica en principio el ingreso al SEIA de dicho proyecto. En caso contrario, este se hace ineludible.

29 Cfr. Historia de la Ley $N^{\circ}$ 20.417, Primer Trámite Constitucional, Cámara de Diputados, Mensaje del Ejecutivo, de fecha 5 de junio de 2008, Cuenta en Sesión 47, Legislatura 356, p. 18.

30 Cfr. Historia de la Ley No 20.417, Informe de Comisión de Recursos Naturales, Cámara de Diputados, de fecha 1 de abril de 2009, Cuenta en Sesión 20, Legislatura 357, opinión del Presidente del Instituto de Ecología, p. 106; opinión del Académico del Instituto de Estudios Urbanos y Territoriales de la Universidad Católica, pp. 117-118; opinión de la Coordinadora de Investigación del Centro de Derecho Ambiental de la Facultad de Derecho de la Universidad de Chile, p. 152.

31 En este sentido, durante la discusión del proyecto de la Ley $\mathrm{N}^{\circ} 20.417$, se valoró como un avance notorio, serio y responsable la introducción de la EAE. Cfr. Discusión en Sala, Cámara de Diputados, Legislatura 357, Sesión 20, de fecha 28 de abril de 2009, pp. 511, 520 a 521, y Discusión en Sala, Senado, Legislatura 357 , Sesión 63, de fecha 10 de noviembre de 2009, p. 1886.

32 Cfr. Historia de la Ley No 20.417, Tercer Trámite Constitucional, Cámara de Diputados, Discusión en Sala, Legislatura 357, Sesión 105, de fecha 11 de noviembre de 2009, p. 1953, Intervención del Diputado Vallespín.

33 Esta norma se complementa con el artículo 15 del Decreto $\mathrm{N}^{\circ} 40$, de 2013, del Ministerio del Medio Ambiente, que aprueba el Reglamento del Sistema de Evaluación de Impacto Ambiental, la cual reproduce íntegramente el mencionado artículo $8^{\circ}$. 
En tal sentido, al artículo $3^{\circ}$ letra g) del Reglamento del Sistema de Evaluación de Impacto Ambiental, señala que deben ingresar a los "Proyectos de desarrollo urbano o turístico en zonas no comprendidas en alguno de los planes evaluados estratégicamente”, entendiéndose por planes a los instrumentos de planificación territorial.

Por último, se debe tener presente que existen muchos de estos instrumentos que contienen decisiones estratégicas y que fueron sometidos al SEIA. En este supuesto el artículo $2^{\circ}$ transitorio del Reglamento del SEIA establece que para tales efectos, "se considerarán evaluados estratégicamente, de conformidad a lo establecido en el párrafo $1^{\circ}$ bis, del Título II de la Ley [19.300], los planes calificados mediante el Sistema de Evaluación de Impacto Ambiental de manera previa a la entrada en vigencia de la Ley $N^{\circ} 20.417$, así como los planes que se encuentren vigentes desde antes de la dictación de la referida Ley $\mathrm{N}^{\circ} 19.300$ ".

\section{EL PROCEDIMIENTO EN LA LEY N 19.300}

\subsection{LA REMISIÓN AL REGLAMENTO}

Tal como sucede respecto de la procedencia de la EAE, la regulación que hace la Ley $\mathrm{N}^{\circ} 19.300$ sobre el procedimiento es la mínima, remitiéndose al reglamento en la regulación de sus etapas y plazos para su tramitación ${ }^{34}$. Como ha ocurrido en otras materias, en este caso la ley establece una regulación básica o general y le entrega al reglamento el desarrollo y complemento de su contenido. Si bien se ha discutido si este tipo de remisiones legislativas se ajustan al principio de reserva legal, la realidad nos demuestra que se han vuelto cada vez más frecuentes y de hecho los reglamentos dictados a su amparo han salvado los controles de constitucionalidad y legalidad ${ }^{35}$. La misma situación se presenta en el derecho comparado, donde más allá de la amplitud o restricción del principio de reserva legal, en materias ambientales se entrega un amplio espacio de actuación a la autoridad administrativa a través de la potestad reglamentaria, lo que en parte descansa en el principio de gradualidad y obedece al carácter eminentemente técnico y multidisciplinario de las temáticas medioambientales.

\subsection{El PROBlema de la AUSENCIA DE REGLAMENTO}

La entrada en vigencia del reglamento que debía complementar las normas sobre EAE planteó también algunos problemas. En primer término, se debía establecer si la ausencia de regulación reglamentaria enervaba la vigencia de las normas legales sobre EAE. En segundo lugar, en caso de que no fuese así, había que determinar las normas que resultaban aplicable en este caso.

Cabe recordar que una situación similar se presentó respecto del SIEA, cuyo reglamento no fue dictado sino hasta 1997, esto es, tres años después de la entrada en vigencia de la Ley Nº 19.300 del año 1994. En dicha oportunidad la Contraloría sostuvo que mien-

\footnotetext{
34 Artículo $7^{\circ}$ ter de la Ley $\mathrm{N}^{\circ} 19.300$.

35 Cfr. Cordero (2009) pp. 409-440. Vid. Dictamen Nº 97.773, de 2014.
} 
tras no se dictara dicho reglamento el SIEA no podría entrar en vigencia ${ }^{36}$. Sin embargo, en este caso se llegó a una solución distinta. La Contraloría ha sostenido en sus dictámenes la plena vigencia de la EAE, la cual debe ser aplicada por la autoridad competente desde la entrada en vigencia de la Ley No 20.417, aun cuando no se haya dictado el reglamento. Así, este vacío normativo se trató de superar con la aplicación supletoria de la Ley $\mathrm{N}^{\circ}$ $19.880^{37}$.

Sin embargo, esta interpretación no fue una solución pacífica, ya que no había pleno acuerdo entre las autoridades administrativas ${ }^{38}$. A su vez, algunos autores entendieron que la regulación del procedimiento de la EAE no podía ser especificada a través de una norma distinta de la potestad reglamentaria del Presidente de la República, lo cual excluiría la aplicación supletoria de una norma de rango legal como lo es la Ley No $19.880^{39}$.

En nuestra opinión, la solución dada por Contraloría fue la correcta no solo desde la perspectiva de las normas aplicables, sino también en relación con la efectiva vigencia de la ley. Además, la propia Contraloría ha sostenido que los reglamentos no tienen la capacidad de desplazar la aplicación de la Ley No 19.880, la cual en estos casos se aplica de forma directa $^{40}$. Con menor razón sería posible afirmar que la ausencia de reglamento también impide su aplicación ${ }^{41}$.

\subsection{El PROCEDIMIENTO de la EAE ante la nUEVA REGLAMENTACión}

La tramitación del Reglamento que regula el procedimiento administrativo de la EAE fue larga y consideró la elaboración de diversos proyectos, que incluso ingresaron a Contraloría para su toma de razón, pero que en definitiva fueron retirados. Así ocurrió con el Decreto $N^{\circ} 17$, de 2013, del Ministerio del Medio Ambiente, que aprobó el Reglamento para la EAE, el cual fue ingresado y retirado de tramitación ante la Contraloría en varias oportunidades para corregir diversas observaciones, siendo su último ingreso el 6 de marzo de 2014 y su toma de razón el 10 de marzo del mismo año, pero que al final no fue publicado $^{42}$. El siguiente texto fue el Decreto $\mathrm{N}^{\circ}$ 60, de 2014, ingresado el 10 de noviembre de 2014, pero fue retirado el 28 de enero de 2015. Finalmente, con fecha 13 de octubre de 2015 fue ingresado a Contraloría el Decreto No 32, de 17 de agosto de 2015, del Ministerio del Medio Ambiente, que Aprueba el Reglamento para la EAE, el que fue tomado razón con fecha 27 de octubre de 2015 y publicado en el Diario Oficial de 4 de noviembre del mismo año.

En este contexto, no se puede sino criticar la lenta y larga elaboración de una reglamentación que en alguna medida ha dificultado la plena aplicación de una institución necesaria para la evaluación estratégica de impactos sinérgicos en temas ambientales claves

\footnotetext{
36 Dictamen No 29.333, de 1996.

37 Carrasco Quiroga (2012) p. 431.

38 Dictamen $\mathrm{N}^{\circ} 78.815$, de 2010.

39 Es la tesis de Guerrero Valle (2012) pp. 109, 113 y 115.

40 Entró otros, vid. Dictamen No 39.348, de 2007.

41 Vid. Dictamen No 39.348, de 2007. En el mismo sentido vid. Carrasco Quiroga (2012) p. 429.

42 Esto obedecería a que la nueva autoridad ambiental habría estimado necesario revisar nuevamente su contenido. Cfr. Troncoso Tirapegui (2014).
} 
-como ya se ha dicho-, y prolongando la incertidumbre acerca de la eficacia de las modificaciones legales.

Por su parte, se debe destacar el rol del Ministerio del Medio Ambiente, que pasó de una función de evaluador técnico a una de colaborador técnico, que opera a solicitud del órgano responsable y, especialmente, en los aspectos que se señalan por el artículo $6^{\circ}$, letra a) del Reglamento, lo que parece más adecuado, dejando las observaciones a la oportunidad procesal correspondiente, esto es, al momento de revisar el informe ambiental del anteproyecto respectivo. En lo que respecta a los demás órganos participantes, se ha eliminado la posibilidad de excusarse de participar en la EAE, considerándose que los "organismos participantes" deben ser convocados obligatoriamente, conforme al artículo 10 del Reglamento, sin perjuicio de la convocatoria facultativa de otros órganos.

\section{LA EAE, INSTRUMENTOS DE INCIDENCIA TERRITORIAL Y LA PLANIFICACIÓN URBANA}

\subsection{LOS INSTRUMENTOS DE INCIDENCIA TERRITORIAL ANTE LA EAE}

La Ley establece los actos que se encontrarán sujetos a EAE, a partir de una regla general (políticas y planes de carácter normativo general), para luego indicar expresamente determinados instrumentos que deberán someterse a este procedimiento. Una característica común de todos estos actos es que se trata de instrumentos de incidencia territorial que materialicen una determinada política pública en una dimensión espacial. A su vez, también dentro de ellos es posible encontrar diferencias. En efecto, por una parte están los instrumentos de planificación territorial previstos en la LGUC (planes regionales de desarrollo urbano, intercomunales, comunales y seccionales) que cuentan con una acabada regulación tanto en la LGUC como en su Ordenanza General, además de una aplicación asentada durante varías décadas desde su regulación a partir de 1929. En cambio, la zonificación del borde costero y del territorio marítimo encuentra como principal instrumento una política aprobada mediante decreto supremo, sin que exista regulación legal específica. Por su parte, los PROTs y los planes de manejo de cuencas carecen de toda regulación.

Si bien este trabajo tiene por objeto analizar los instrumentos de planificación territorial previstos en la LGUC, vamos a hacer una breve referencia a estos instrumentos carentes de regulación legal específica.

\section{A) El Plan Regional de Ordenamiento Territorial (PROT)}

El PROT está estrechamente unido al concepto de ordenación del territorio y representa la aspiración de avanzar de forma decisiva a un nivel de planificación que sea la expresión espacial de la política económica, social, cultural y ambiental, siguiendo al efecto el modelo europeo, particularmente el que se encuentra contenido en la Carta Europea de Ordenación del Territorio de 1983. Sin embargo, ni la Constitución ni la Ley No 19.175, de Gobierno y Administración Regional (LGAR) recogen competencia alguna sobre orde- 
nación del territorio ${ }^{43}$. Es así que para introducir expresamente esta función-competencia se presentó un proyecto de ley que incorporaba este nuevo instrumento, el que debería "[...] consignar las características, potencialidades, vocaciones y recomendaciones para orientar la planificación y las decisiones que impacten en los territorios urbanos y rurales, borde costero y sistema de cuencas hidrográficas" ${ }^{44}$. A su vez, la iniciativa proponía eliminar de nuestro ordenamiento el PRDU, cuyo lugar lo pasaría ocupar justamente el PROT. Como consecuencia de lo anterior, en el proyecto de ley sobre nueva institucional ambiental se consideró al PROT como un instrumento de planificación territorial, a fin de someterlo al sistema de evaluación estratégica y así quedó establecido en el inciso $2^{\circ}$ del artículo 7 bis de la Ley No 19.300, modificada por la Ley No 20.417. Sin embargo, el proyecto que regulaba los PROT todavía sigue en tramitación sin que haya experimentado ningún avance sustantivo, por lo que solo es reconocido en la Ley No 19.300, pero no tiene una regulación legal que determine las autoridades que deben intervenir en su aprobación, el procedimiento y sus efectos.

No obstante lo anterior, algunos actores públicos y privados han entendido que este instrumento se podría diseñar e implementar en Chile sin necesidad de una regulación legal específica. Así, el Gobierno Regional de Aysén aprobó en el año 2006 un reglamento regional marco de planificación de Aysén ${ }^{45}$. En dicho cuerpo normativo se consideró al PROT como una figura distinta de los instrumentos regulados en la Ley General de Urbanismo y Construcciones. En la misma línea, la Subsecretaría de Desarrollo Regional, a través del Departamento de Políticas de Descentralización de la División de Políticas y Estudios, publicó en febrero del año 2010 un estudio sobre el PROT, dando cuenta de sus principios orientadores, condiciones que debe cumplir, resultados esperados, estructura y contenido, partiendo de la base de que este instrumento habría sido creado por la citada

\footnotetext{
43 Se debe tener presente que la ordenación del territorio es un concepto distinto de la función específica que en materia de ordenamiento territorial se asigna a los gobiernos regionales, contenido en el artículo 17 LGAR. La ordenación del territorio responde a una tradición europea que aspira a plasmar espacialmente las políticas económicas, sociales, culturales y ecológicas. A su vez sus objetivos están centrados en tres puntos: desarrollo económico y equilibrado de las regiones, mejoramiento de la calidad de vida de las personas y la protección del medio ambiente. Todo esto se engloba bajo la idea de una utilización racional del territorio, lo cual exige una planificación como instrumento necesario y esencial. En tal sentido, la Carta Europea de Ordenación del Territorio de 1983 la define como: "la expresión espacial de la política económica, social, cultural y ecológica de toda sociedad. Es a la vez una disciplina científica, una técnica administrativa y una política concebida como un enfoque interdisciplinario y global, cuyo objetivo es un desarrollo equilibrado de las regiones y la organización física del espacio según una estrategia global”. Vid. Pérez (1997) p. 24, y Parejo Alfonso(1998) pp. 305 y ss.

44 Mensaje Presidencial 128-3586 de 8 de abril de 2008. Actualmente se está tramitando como Boletín No 5872-06 en la Comisión de Gobierno, Descentralización y Regionalización del Senado, desde el 30 de junio de 2008 , sin que tenga urgencia.

45 Resolución No 46, de 2006, del Intendente Regional. No obstante lo anterior, la Contraloría General de la República ha sido categórica en señalar que este instrumento no tiene existencia legal en Chile y que su eventual implementación sobrepasa las facultades de los gobiernos regionales. Cfr. Dictamen No 59.316, de 2006
} 
Ley No $20.417^{46}$. De hecho, a la fecha se están sometiendo a EAE 16 proyectos de PROTs, de los cuales dos han tenido un avance sustantivo ${ }^{47}$.

En un trabajo anterior ya hemos planteado nuestras dudas respecto de la necesidad de introducir la figura del PROT, existiendo otro instrumento que ha cumplido la misma finalidad u objetivo, como es el PRDU, ya que un examen de los mismos nos permite apreciar que una regulación integrada de los usos en el suelo urbano y rural se cumple a cabalidad en dichos planes ${ }^{48}$. Además, los PRDU también asumen la función de indicar lineamientos y, a la vez, constituir un importante instrumento de coordinación entre los diversos organismos públicos que tienen competencias de incidencia territorial en la región ${ }^{49}$.

\section{B) Zonificación del borde costero y del territorio maritimo}

El tema de la zonificación del borde costero está vinculado en Chile a la Política Nacional del Uso del Borde Costero (PNUBC), aprobada por Decreto Supremo No 475, de 1994, del Ministerio de Defensa Nacional. En sus fundamentos, dicha política se formula sobre la base a tres grandes objetivos: i) propender a un uso adecuado del borde costero; ii) establecer una institucionalidad o marco orgánico; y iii) la conveniencia de establecer mecanismos de coordinación.

Para tal efecto se creó una Comisión Nacional de Uso del Borde Costero (CNUBC) que le corresponde proponer una zonificación de los diversos espacios que conforman el Borde Costero del Litoral de la República. A su vez, en virtud de lo establecido en un Instructivo presidencial de 1997, esta entidad se desconcentra territorialmente en Comisiones Regionales de Uso del Borde Costero (CRUBC), que son creadas por resolución de los Intendentes ${ }^{50}$.

Conforme a estas normas, once zonas costeras del país han sido objeto de zonificación al amparo de estas normas, siendo declaradas de uso preferente (portuario o turístico); reservadas para determinados usos o, en su caso, calificadas como zonas protegidas. Sin embargo, si bien constituye un aspecto positivo la zonificación del borde costero, existen serios reparos en relación a la ausencia de una regulación legal de esta materia y el carácter estrictamente asesor de las CNUBC y CRUBC sin potestades o atribuciones públicas directas. Además, aquello hace que la zonificación del borde costero adquiere el carácter de plan

\footnotetext{
46 Subsecretaría de Desarrollo Regional (2010). El texto fue elaborado en el período 2009-2010 por especialistas del Departamento de Políticas Públicas y Descentralización de la SUBDERE, de la Universidad de Chile y de Cepal. Hay una segunda edición del año 2011 que se puede consultar en http://www.subdere.gov.cl/ sites/default/files/documentos/articles-83896_recurso_1_1.pdf

47 Corresponde a los PROTs de las Regiones de Tarapacá y del Maule. Se puede consultar en http://eae.mma. gob.cl/index.php/ficha

48 Cfr. Plan Regional de Desarrollo Urbano, II Región, aprobado por resolución No 7, de 1 de marzo de 2005 (DO. de 10 de junio de 2005); y el Plan Regional de Desarrollo Urbano de la Región de Coquimbo, aprobado por resolución No 14, de 09 de marzo de 2006 (DO. 19 de diciembre de 2006).

49 Cfr. Cordero (2011) pp. 209-249, en particular las pp. 236-238.

50 En el año 1997 se dictó el Instructivo Presidencial No 1, que consideró la creación de las CRUBC, sujetas a una resolución del Intendente Regional. Durante el mismo año se constituyeron las diversas comisiones a nivel regional y su funcionamiento quedó sujeto a un Oficio del Gabinete del Presidente No 001, del mismo año. Este fue modificado el 28 de febrero de 2005.
} 
indicativo y no vinculante, siendo desplazado ante otras regulaciones, como sucede con los Instrumentos de Planificación Territorial, vgr. PRDU, PRI, PRC, salvo en aquellos casos excepcionales previstos por la ley ${ }^{51}$.

En definitiva, el valor que tiene la zonificación del uso del borde costero es limitado y su eficacia es secundaria frente a otros instrumentos de zonificación, como son los PRDU, PRI y PRC. Ahora bien, y sin perjuicio de lo señalado, ante la ausencia de una regulación legal acabada, la incorporación de estos instrumentos a la EAE constituye un avance importante al momento de formular una política pública en relación a la zonificación de nuestro litoral.

\section{C) Los planes de manejo de cuencas}

El problema de la gestión y manejo de cuencas ha tenido en nuestro país distintas etapas y énfasis. En una primera fase en los años 70 estuvo vinculado al manejo forestal, de pastos, nieves y general en la búsqueda de cierto control sobre las corrientes de agua, lo cual también permitía frenar la erosión de los suelo ${ }^{52}$. Por lo demás, esta perspectiva de análisis ya se venía desarrollando en los Estados Unidos a partir de 1930, donde se acuña la expresión Watershed Management ${ }^{53}$. En una fase posterior se vincula con objetivos más amplios en materia ambiental, de ordenación del territorio y desarrollo regional, que tiene como referencia cronológica la década de los 80 , a partir de un programa auspiciado por la FAO a través de una Red Latinoamericana de Cooperación Técnica en Manejo de Cuencas Hidrográficas (REDLACH), hasta llegar a la década de los 90 en la formulación de un manejo integrado de cuencas hidrográficas ${ }^{54}$.

Durante la primera etapa en Chile se hizo un diagnóstico y se identificaron cuencas críticas, que en una segunda fase dieron lugar a la ejecución de proyectos que permitieran un mejor manejo de los recursos naturales renovables a nivel de cuencas hidrográficas. Sin embargo, no ha existido en nuestro país una normativa específica que se haga cargo de la regulación y de planificación de las cuencas, lo que no ha impedido que se hayan formulado algunas iniciativas a nivel de políticas respecto de su zonificación ${ }^{55}$.

\footnotetext{
51 Al efecto podemos mencionar dos casos: i) cuando en virtud de normas legales -especialmente contenidas en tratados internacionales- el Presidente de la República puede declarar un área marina y costera protegida; y ii) cuando la ley expresamente lo ha dispuesto, como ocurre con la Ley No 18.892, General de Pesca y Acuicultura, cuyo texto refundido, coordinado y sistematizado se encuentra en el Decreto Supremo No 430, de 2001, del Ministerio de Economía, Fomento y Reconstrucción. Al efecto, su artículo 2 No 57 define la zonificación del borde costero, haciendo una referencia expresa a la PNUBC. A su vez, el artículo 67 del mismo cuerpo legal establece que la zonificación del borde costero es vinculante al momento de otorgar una concesión de acuicultura. Se debe señalar, en todo caso, que estas disposiciones fueron introducidas por la Ley No 20.434, de 8 de abril de 2010. La razón se encuentra en los pronunciamientos de la Contraloría General de la República en relación al otorgamiento de concesiones de acuicultura. El ente contralor señaló expresamente que la zonificación del borde costero no era una norma que pudiera condicionar el otorgamiento de dichas concesiones, dada su naturaleza. Véanse, entre otros, dictámenes $\mathrm{N}^{\circ}$ s. 23.897, de 27 de junio de 2002, y 865, de 7 de enero de 2005.

52 Esta primera perspectiva se puede ver en FrancKe CAMPaña (2002) p. 6.

53 Cfr. Heatchсоте (2009).

54 Francke Campaña (2002) pp. 6-7.

55 Subsecretaría de Desarrollo Regional (2013).
} 
En este caso, el análisis de las cuencas desde una perspectiva territorial guarda estrecha relación con los crecientes problemas ambientales, sociales y económicos que se producen como consecuencia del desabastecimiento hídrico en un número importante de zonas del país, una sequía prolongada, el cambio de patrones de precipitación, el deterioro de los glaciares, la conflictividad por el agua, la sobreexplotación y subutilización de los recursos hídricos, y la afectación de hábitats y nichos ecológicos relevantes vinculados a una cuen$\mathrm{ca}^{56}$. En todo caso lo que se gestiona o se maneja no es la cuenca en sí misma ni los elementos que lo componen, sino que las intervenciones del ser humano sobre ellos, especialmente la actuación de los órganos y servicios públicos, que requiere sercoordinada.

También el ingreso de Chile a la OCDE ha sido importante, ya que dentro de las recomendaciones que se formularon se señaló expresamente la necesidad de "desarrollar un enfoque integrado de gestión de cuencas para mejorar el manejo de los recursos hídricos y forestales y para proporcionar servicios ambientales con más eficiencia" ${ }^{7}$, lo que también era consecuencia de recomendaciones formuladas en diversas instancias a nivel internacional $^{58}$. Así, en el año 2007 se aprobó una "Estrategia de Gestión Integrada de Cuencas Hidrográficas" con un componente institucional (Consejo Ministerial, Secretaria Técnica y Organismos de Cuencas), un componente instrumental (Plan de Gestión de Cuencas) y un componente de información (monitoreo y línea de base económica, social y ambiental), además de implementar su aplicación en tres cuencas piloto (río Copiapó, río Rapel y río Baker), pero en que definitiva no mantuvo continuidad ${ }^{59}$.

Es por esta razón es que a partir del año 2013 se ha previsto que la regulación de estos espacios se enmarque en el PROT, el cual debiera considerar cuatro componentes básicos: componente rural, componente urbano, componente costero y componente hidrográfico $^{60}$, a pesar de los reparos que plantea un instrumento que carece de regulación legal y que es de una lenta elaboración. En todo caso, la planificación a nivel de cuencas constituye una necesidad que debe ser enfrentada en el máximo nivel normativo, especialmente frente a un sistema en la asignación y gestión de los recursos hídricos que no considera necesariamente estos elementos ${ }^{61}$.

\subsection{BREVE REFERENCIA A LA PLANIFICACIÓN TERRITORIAL}

Los instrumentos de planificación territorial se encuentran regulados en la LGUC, cuyo artículo 27 define la planificación urbana como el proceso que se efectúa para orientar y regular el desarrollo de los centros urbanos en función de una política nacional, regional

\footnotetext{
56 Subsecretaria de Desarrollo Regional (2013) p. 6.

57 Organización de Cooperación y Desarrollo Económicos y Comisión Económica para América latina y el CARibe (2005) p. 68.

58 Así, en la Conferencia Internacional de las Naciones Unidas sobre Gestión Integrada de Recursos Hídricos celebrada en Tokio, Japón, en diciembre de 2004 y en el Foro Mundial del Agua, celebrado en Ciudad de México el 22 de marzo 2006.

59 Cfr. Vergara Blanco (2008).

60 Subsecretaría de Desarrollo Regional (2013) p. 8.

${ }^{61}$ Cfr. Vergara Blanco (2014).
} 
y comunal de desarrollo socioeconómico, cuyos objetivos y metas serán incorporados en la planificación urbana en todos sus niveles ${ }^{62}$.

Tal planificación se plasma, por una parte, en los PRDU que orientan el desarrollo de los centros urbanos en las regiones, fijando los roles de los centros urbanos, sus áreas de influencia recíproca, relaciones gravitacionales, metas de crecimiento, entre otros aspectos. Su confección corresponde a las Secretarías Regionales de Vivienda y Urbanismo, de acuerdo con las políticas regionales de desarrollo socioeconómico, debiendo sus disposiciones incorporarse en la planificación inferior, esto es, en los planes reguladores metropolitanos, intercomunales y comunales ${ }^{63}$.

Por su parte, tanto los PRI como los PR metropolitanos tienen por objeto hacer efectiva la planificación urbana intercomunal y están constituidos por un conjunto de normas y acciones para orientar y regular el desarrollo físico del área -urbana y rural-correspondiente a diversas comunas que, por sus relaciones, se integran en una unidad urbana ${ }^{64}$.

A su vez, los PRC hacen efectiva la planificación urbana comunal, cuyo objeto es promover el desarrollo armónico de ese territorio, en especial de sus centros poblados en concordancia con las metas regionales de desarrollo económico-social y están constituidos por un conjunto de normas varias que, entre otros aspectos, se refieren al uso del suelo o zonificación, fijación de límites urbanos, densidades y determinación de prioridades en la urbanización de terrenos para la expansión de la ciudad y demás aspectos urbanísticos ${ }^{65}$.

Por último, los Planes Seccionales tienen por objeto la realización de los estudios más detallados que la aplicación de un Plan Regulador Comunal requiera, pudiendo fijar, por ejemplo, la zonificación detallada, las áreas de construcción obligatoria, de remodelación, conjuntos armónicos, terrenos afectados por expropiaciones. La confección de tales planes será procedente de acuerdo con los criterios que al efecto establece la ley ${ }^{66}$.

\subsection{El tratamiento ambiental de la planificación terRitorial EN NUESTRA} LEgislación y el rol de la Contraloría General de la República

Para poder comprender el impacto de la incorporación de la EAE en nuestra legislación ambiental respecto de la planificación territorial, conviene revisar la regulación original de la materia. En efecto, en el catálogo de proyectos o actividades susceptibles de causar impacto ambiental, en cualesquiera de sus fases, y que debían someterse al SEIA conforme al texto original de la letra h) del artículo 10 de la Ley No 19.300 incluía a los PRDU, PRI, PRC, planes seccionales, proyectos industriales o inmobiliarios que los modifiquen o que se ejecuten en zonas declaradas latentes o saturadas ${ }^{67}$. Sin embargo, luego de las modifica-

\footnotetext{
62 Sobre la planificación territorial y la jurisprudencia de la Contraloría vid. Contraloría General de la República (2012). También se puede ver Cordero (2007) pp. 269-298, y RAJEVIC Mosler (2001) pp. 81-100.

63 Artículos 30 al 33.

64 Artículos 34 al 40.

65 Artículos 41 al 51.

66 Artículo 46.

67 Cfr. Toledo Tapia (1996) p. 64, donde se explica que el texto citado de la letra h) del artículo 10 de la Ley $\mathrm{N}^{\circ} 19.300$ fue producto de una indicación de los senadores Diez, Piñera y Siebert, la que fue finalmente aprobada por la Cámara de Diputados.
} 
ciones realizadas por la Ley $\mathrm{N}^{\circ} 20.417$, la planificación territorial no quedó comprendida dentro del SEIA, quedando sujeta a la EAE. Esta solución resultaba de toda lógica y daba respuesta a las permanentes críticas que existían al respecto, ya que este sistema no se correspondía con la naturaleza propia de estos instrumentos y a la necesidad de evaluarlos desde la perspectiva de las políticas públicas de incidencia territorial.

Por su parte, en su implementación se ha presentado una serie de dificultades de las cuales ya hemos dado cuenta, y en el que ha jugado un rol relevante la jurisprudencia administrativa sentada por la Contraloría.

\section{LA JURISPRUDENCIA ADMINISTRATIVA RECAÍDA SOBRE LA MATERIA}

En razón de las competencias que se atribuye a la Contraloría respecto de las problemáticas jurídicas asociadas a la planificación territorial, es que se ha debido pronunciar acerca de la EAE luego del cambio de régimen introducido por la Ley No 20.417 .

\subsection{La EAE ante el Procedimiento de la Ley Nº 19.880, de 2003}

La aplicación de la Ley No 19.880 a este procedimiento estuvo vinculada al problema de vacío normativo que se presentó ante la ausencia del Reglamento para la EAE, que se dictó el año 2015. En el caso de los instrumentos de planificación territorial regulados en la LGUC no existía acuerdo entre la autoridad urbanística y ambiental, por lo que la cuestión fue zanjada por la Contraloría al establecer que "desde la fecha de publicación de la ley $\mathrm{N}^{\circ} 20.417$, los planes reguladores comunales y sus modificaciones, no están obligados a someterse a evaluación de impacto ambiental, y que con arreglo a lo dispuesto en el inciso final de su artículo primero transitorio, aquellos sometidos a esa evaluación antes de dicha oportunidad, se sujetarán en su tramitación y aprobación a las normas vigentes al momento de su ingreso". Agrega el referido pronunciamiento que la EAE debe ser aplicada por la autoridad pertinente aun cuando no se haya dictado el reglamento que prescribe la ley, puesto que mientras esté pendiente su dictación la institución está plenamente vigente y debe, conforme a lo dispuesto en el artículo $1^{\circ}$ de la Ley $\mathrm{N}^{\circ} 19.880$, aplicarse supletoriamente las normas de este último cuerpo legal ${ }^{68}$.

Por nuestra parte, compartimos plenamente el criterio de dar aplicación directa a las normas legales, no condicionando su vigencia a normas administrativas posteriores, más aún si la propia ley no la restringe y existen elementos que permitan llenar los eventuales vacíos en la regulación. Por su parte, si bien la demora en la dictación del reglamento pudo haber afectado su plena aplicación, buena parte de los problemas se han resuelto mediante la aplicación supletoria de la Ley $\mathrm{N}^{\circ} 19.880$ y por la vía de una Circular conjunta de los Ministerios de Vivienda y Urbanismo y de Medio Ambiente ${ }^{69}$.

68 Dictamen $\mathrm{N}^{\circ} 78.815$, de 2010.

69 Circular Ord. No 0254, DDU 247, de 8 de abril de 2011. 


\subsection{AlCANCE DE LA JURisprudencia}

Otro problema se presentó con aquellos instrumentos que fueron sometidas al SEIA con fecha posterior a la introducción de la EAE. En este caso la Contraloría decidió resolver el problema aplicando el principio de buena fe, señalando que su Dictamen $N^{\circ} 78.815$, de 28 de diciembre de 2010, solo era aplicable hacia el futuro, no afectando los instrumentos de planificación territorial que habían sido sometidos al SEIA después de la entrada en vigencia de la Ley $\mathrm{N}^{\circ} 20.417$, de 2010, pero antes del Dictamen $\mathrm{N}^{\circ} 78.815$, de $2010^{70}$.

De este modo, respecto de los planes ingresados al SEIA después del 26 de enero del 2010, pero antes del 28 de diciembre de 2010, hay que distinguir entre los que han obtenido una Resolución de Calificación Ambiental (RCA) antes de esta última fecha y los que no. En el primer caso, conforme a lo aclarado por la Contraloría, dichos planes no se encuentran obligados a obtener la EAE. En el segundo caso, estando pendiente su aprobación en el SEIA, no será exigible la EAE, toda vez que ello significaría trasgredir el amparo que el principio de buena fe brinda a las reparticiones públicas que actuaron conforme al criterio sostenido a la data por la autoridad ambiental. Distinto es el caso de los instrumentos ingresados al SEIA después del 28 de diciembre de 2010, los cuales deben ser sometidos a la EAE.

Posteriormente, se confirmó que según lo dispuesto por el inciso tercero del artículo primero transitorio de la Ley $\mathrm{N}^{\circ} 20.417$, los proyectos o actividades sometidos al SEIA previo a la publicación de dicha ley -esto es, antes del 26 de enero de 2010-, se sujetarían en su tramitación y aprobación a las normas vigentes al momento de su ingreso, razón por la cual los instrumentos de planificación territorial ingresados al SEIA antes de dicha ley no están obligados a someterse además a la $\mathrm{EAE}^{71}$.

Por último, también se dejó establecido que dicho criterio es igualmente aplicable a los proyectos en que el titular es del sector público y que los instrumentos ingresados al SEIA por la autoridad que tiene a su cargo la planificación territorial antes del dictamen, podían ser evaluados solo por este medio, confirmando la aplicación del principio de buena $\mathrm{fe}^{72}$.

\subsection{El CONCEPTO DE MODIFICACIÓN SUSTANCIAL}

Aclarado el tema de la procedencia de la EAE, la jurisprudencia se ha hecho cargo del tratamiento de las "modificaciones sustanciales" a los instrumentos de planificación territorial vigentes. Como ya se ha indicado, se trata de un concepto que no ha sido definido por la ley y cuyo alcance fue abordado en las diversas versiones del reglamento actual. En el intertanto la materia fue abordada mediante la Circular Ord. No 0254, DDU 247 que aprobó la "Guía para la Evaluación Ambiental Estratégica de los instrumentos de planifica-

\footnotetext{
70 Dictamen $N^{\circ}$ 41.275, de 2011. Cfr. Carrasco Quiroga (2012) pp. 434-435, quien habla de modificación o cambio de criterio, en circunstancias que en estricto rigor lo que hace este pronunciamiento es mantener el criterio del Dictamen $\mathrm{N}^{\circ} 78.815$, de 2010, aclarando los efectos de su aplicación concreta según los casos que se analizan.

71 Dictamen $N^{\circ}$ 65.497, de 2011.

72 Dictamen $\mathrm{N}^{\circ} 78.248$, de 2011.
} 
ción territorial”73, estableciendo criterios que en parte coincidían con los definidos por la jurisprudencia de Contraloría, así como los del actual reglamento ${ }^{74}$.

Por otra parte, la Contraloría también ha establecido una regla muy importante respecto de la fundamentación para justificar la exclusión de la EAE: la autoridad a cargo de la planificación territorial debe justificar, de manera suficiente, que las modificaciones que efectúa a los planes no tienen el carácter de sustanciales, para de este modo poder omitir la $\mathrm{EAE}^{75}$. Así, por ejemplo, la autoridad debe acreditar suficientemente que la ampliación del límite de extensión urbana no tiene el carácter de modificación sustancial ${ }^{76}$, lo mismo que las medidas que aumentan la densidad y el coeficiente de constructibilidad ${ }^{77}$. Además, se ha establecido un estándar de fundamentación más elevado, no aceptando meros enunciados o justificaciones que no tengan un carácter sustancial ${ }^{78}$.

Así, la jurisprudencia administrativa ha ido establecido criterios para dar contenido a los conceptos utilizados por la ley ${ }^{79}$, como ocurre con la expresión "modificaciones sustanciales". A su vez, el reglamento solo se hace cargo del tema respecto de los instrumentos de ordenamiento territorial ${ }^{80}$.

\subsection{La CONSUlTa PÚBlica}

En esta materia la Contraloría ha sostenido el carácter obligatorio de la consulta pública en los instrumentos sometidos a $\mathrm{EAE}^{81}$ a partir de la entrada en vigencia de la Ley No 20.417. Además, ha señalado los elementos de forma y fondo que deben cumplir estos instrumentos, como son las consideraciones ambientales y de desarrollo sustentable que debe incorporar la política o plan para su dictación, así como los criterios e indicadores de seguimiento destinados a controlar la eficacia del plan o política, y los criterios e indicadores de rediseño que se deberán considerar para la reformulación de dicho plan o política en el mediano o largo plazo ${ }^{82}$. Además, se ha señalado que no basta solo indicar en el acto

\footnotetext{
73 Esta Guía, conocida como la DDU 247, suscrita por las Ministras de Medio Ambiente y Vivienda y Urbanismo, ha sido ampliamente difundida a través de la Circular Ordinario N² 254, de 8 de abril de 2011, de la División de Desarrollo Urbano, del Ministerio del rubro, encontrándose disponible electrónicamente en el portal del Ministerio de Medio Ambiente, http://portal.mma.gob.cl/evaluacion-ambiental-estrategica/. En todo caso, dicha guía fue dejada sin efecto por la Circular Ord. No 0551, DDU 298, de 9 de diciembre de 2015, por la entrada en vigencia del nuevo reglamento.

74 Dictamen $N^{\circ}$ 27.856, de 2005, y sus posteriores aplicaciones mediante Dictámenes $\mathrm{N}^{\circ}$ s. 45.330, de 2008 y 31.287, de 2012. Sobre jurisprudencia ambiental de la Contraloría vid. VARGas Delgado (2006) pp. 31-45.

75 Dictamen $\mathrm{N}^{\circ} 145$, de 2013.

76 Dictamen $\mathrm{N}^{\circ} 6.271$, de 2013, observación $\mathrm{N}^{\circ} 24$.

77 Dictamen $\mathrm{N}^{\circ} 17.486$, de 2013, observación $\mathrm{N}^{\circ} 2$.

78 Dictamen $\mathrm{N}^{\circ} 36.816$, de 2013.

79 Para la jurisprudencia reciente que aplica los criterios jurisprudenciales comentados, véanse los Dictámenes $\mathrm{N}^{\circ}$ s.70.559, de 2012; 74.747, de 2013; 83.151 y 99.760, de 2014.

80 Artículo 29 del Reglamento para la EAE.

81 Dictámenes $\mathrm{N}^{\circ}$ s. 48.885, 49.074 y 66.458, todos de 2013, y los Dictámenes Nº. 1.765, 11.429 y 30.171, todos de 2014

82 Cfr. Dictámenes $N^{\circ}$ s. 14.462, 30.171, 39.390 y 64.423, todos de 2014. Sobre los aspectos formales se ha hecho presente la falta de firma de la autoridad respectiva en el informe ambiental de rigor, vid. Dictámenes $\mathrm{N}^{\circ}$ s. 66.458 y 73.730, ambos de 2013, y los Dictámenes $\mathrm{N}^{\circ}$ s. 1.765, 11.429 y 30.171, todos de 2014.
} 
administrativo que se ha realizado la consulta pública con una simple referencia a los antecedentes contenidos en el expediente administrativo, sin dar cuenta de la forma en que esta ha sido considerada ${ }^{83}$.

En el actual reglamento la consulta pública ha sido abordada en los artículos 24 y 25 , tanto para el anteproyecto de política, plan o instrumentos de ordenamiento territorial, como respecto de las modificaciones que a él se introduzcan a propósito del Informe Ambiental Corregido. En este caso, la participación ciudadana es amplia, ya que que cualquier persona puede formular observaciones, pero sus efectos son limitados, en medida que una vez recibidas el órgano responsable solo deberá analizar dichas observaciones y señalar en la resolución de término la forma en que han sido consideradas, cuestión que fue objeto de una intensa discusión durante la tramitación legal de la $\mathrm{EAE}^{84}$.

\section{CONCLUSIONES}

La evaluación de las políticas públicas, los planes y normas debemos entenderlo como una necesidad que plantea la buena gobernanza al momento de adoptar decisiones estratégicas, que van a tener una importante incidencia social y cuyos alcances deben ser medidos antes, durante y después de su implementación en todas sus dimensiones, a fin garantizar la mayor eficiencia y eficacia para alcanzar los objetivos que se ha planteado la autoridad. En este contexto, la EAE constituye sin lugar a dudas un aporte sustantivo en la formulación de las políticas, planes y normas con el objetivo de alcanzar un desarrollo sustentable en el marco de la preservación de los recursos naturales, que por lo demás son deberes que la Constitución impone a los poderes públicos.

Desde una dimensión amplia, debemos entender que la EAE es un proceso estructurado y proactivo para fortalecer el papel de las cuestiones ambientales en la toma de decisiones estratégicas. Desde la perspectiva jurídica entendemos que se trata de un procedimiento que, estando a cargo de la misma autoridad que elabora la política, plan o programa, debe coordinarse con el procedimiento principal y con otras autoridades competentes, especialmente las ambientales, a fin de incorporar las variables o consideraciones ambientales de desarrollo sustentable al proceso de formulación de la política, plan o programa, desde el diseño o preparación de los mismos.

En cuanto a su procedencia, nuestra legislación comprende a toda política y plan de carácter normativo general, haciendo mención expresa de los instrumentos de incidencia territorial. A su vez, dentro del concepto general, hemos entendido que una "política de carácter normativo general" sería aquella que contempla las orientaciones o directrices que regirán la actuación de una entidad pública en un asunto o campo determinado. A su vez, "plan de carácter normativo general" corresponde al conjunto de pasos o etapas ordenadas anticipada y sistemáticamente para dirigir y encauzar la actuación de una entidad pública en orden a un objetivo o fin determinado. No obstante, nuestra legislación somete a EAE

\footnotetext{
83 Dictamen $\mathrm{N}^{\circ} 34.481$, de 2014.

84 En ese caso se discutió el carácter vinculante de la participación ciudadana en las EAE. Cfr. Historia de la Ley No 20.417, Biblioteca del Congreso Nacional, pp. 752-790.
} 
no solo la aprobación de estos instrumentos, sino también toda "modificación sustancial", que en nuestra opinión son aquellas reformas que afectan los elementos básicos o esenciales de una política pública o un plan.

Por otra parte, la implementación de este sistema de evaluación ha sido paulatina, aunque la jurisprudencia administrativa ha reconocido la vigencia inmediata de la Ley No 20.417, que la introdujo en nuestro ordenamiento. Por tal razón, el actual reglamento recoge la práctica administrativa existente a la época, especialmente aquella emanada de la jurisprudencia administrativa y de las normas internas dictadas por las autoridad administrativas.

En nuestro análisis hemos distinguido entre los instrumentos de incidencia territorial y los instrumentos de planificación territorial. Todos estos se caracterizan porque tienen por finalidad materializar una determinada política pública en una dimensión especial. Sin embargo, entre ellos hay diferencias importantes en su regulación y aplicación, que plantean problemas en cuanto a sus efectos y a la falta de instrumentos de gestión más incisivos que requieren de potestades públicas expresamente previstas por la ley.

Ahora bien, las cuestiones prioritarias que se presentarán con esta nueva normativa dicen relación con la aplicación de sus disposiciones a los instrumentos que se encuentren pendientes de evaluación al momento de su entrada en vigencia, que de forma adecuada es abordada por sus disposiciones transitorias ${ }^{85}$, lo que no es óbice al planteamiento de alguna discusión respecto de su alcance y de la existencia de futuros pronunciamientos de la Contraloría sobre la materia. Por otra parte, tampoco es posible discutir la validez de los instrumentos aprobados bajo el régimen establecido por los criterios de Contraloría y la práctica normativa, aunque sus futuras modificaciones sustanciales necesariamente deberán ser sometidas a la EAE conforme lo dispuesto en el nuevo reglamento.

Finalmente, ante la ausencia de una política nacional en materia ambiental, pensamos que la EAE constituirá un importante instrumento que permitirá ir delineando una suerte de política ambiental específica en diversos ámbitos, especialmente en lo que dice relación con los instrumentos de incidencia territorial, que no son sino la expresión espacial de las políticas públicas que el Estado formula en el ámbito social, económico, cultural y ambiental.

En definitiva, no cabe duda que la EAE constituye un instrumento necesario e idóneo respecto de las políticas, planes y normas de carácter general para determinar y prevenir los efectos de incidencia ambiental que pueden producir. A su vez, las dificultades que ha planteado su aplicación no guardan una necesaria relación con la vigencia efectiva de su marco normativo, ya que se ha reconocido la vigencia inmediata de la Ley No 20.417, entregándose una serie de criterios y herramientas que permiten su aplicación aun ante la ausencia de un reglamento, lo cual no ha cambiado sustancialmente desde su entrada en vigencia. Por tal razón, pensamos que los problemas que ha tenido su implementación son los propios de un procedimiento administrativo complejo, que hace más lenta la adopción de decisiones públicas, ante un cambio de la cultura interna de los servicios y los mayores tiempos que exige el aprendizaje inicial.

${ }^{85}$ Artículo Transitorio del Reglamento para la EAE. 


\section{BIBLIOGRAFÍA CITADA}

Carrasco Quiroga, Edesio (2012): "Evaluación ambiental estratégica y procedimiento administrativo: legalidad, supletoriedad y funcionalidad", en Revista Actualidad Jurídica, $N^{\circ}$ 25, enero 2012: pp. 421-438.

Clark, Brian D. (1997): "Alcances y objetivos de la Evaluación Ambiental Estratégica (EAE)”, Estudios Públicos, No 65: pp. 1-22.

Cordero Quinzacara, Eduardo (2007): "El derecho urbanístico: los instrumentos de planificación territorial y el régimen jurídico de los bienes públicos", Revista de Derecho de la Pontificia Universidad Católica de Valparaíso, XXIX: pp. 269-298.

Cordero Quinzacara, Eduardo (2009): "El sentido actual del dominio legal y la potestad reglamentaria", Revista de Derecho de la Pontificia Universidad Católica de Valparaiso, XXXII: pp. 409-440.

Cordero Quinzacara, Eduardo (2011): “Ordenamiento territorial, justicia ambiental y zonas costeras", Revista de Derecho de la Pontificia Universidad Católica de Valparaíso, No 36: pp. 209-249.

Contraloría General de la República (2012), Manual Práctico de jurisprudencia administrativa sobre planes reguladores comunales, intercomunales y metropolitanos (Santiago, Contraloría General de la República, primera edición).

Dalal-Clayton, Barry y Sadler, Barry (2005): Strategic Enviromental Assessment. A sourcebook and reference guide to international experience (Londres, Earthschan).

Francke Campaña, Samuel (2002): La situación del manejo de cuencas en Chile (Santiago, CONAF-Ministerio de Agricultura).

Fischer B. Thomas (2007): The Theory and Practice of Strategic Environmental Assessment: Towards a More Sistematic Approach (Londres, Earthschan).

Guerrero Valle, Gonzalo (2012): "La evaluación ambiental estratégica: Desafíos y propuestas tras su incorporación al ordenamiento jurídico chileno", Revista de Derecho Público, vol. 77: pp. 99-119.

Heatchсоте, Isobel W. (2009): Integrated Watershed Managemen. Principles and practice (New Jersey, Wiley, segunda edición).

Jacquenod de Zsögon, Silvia (2001): Derecho Ambiental, Preguntas y respuestas (Madrid, Dykinson, primera edición).

Jiménez Bueso, Álvaro (2014): "Resumen de reciente doctrina jurisprudencial sobre evaluación ambiental estratégica y evaluación de impacto ambiental de planes urbanísticos" en Jornadas sobre interpretación y aplicación de las sentencias judiciales en materia de urbanismo y ordenación del territorio, 22 y 23 de octubre de 2014 (Madrid, Comunidad de Madrid). Disponible en www.madrid.org/, Comunidad de Madrid, Consejería de Medio Ambiente y Ordenación del Territorio, Dirección General de Urbanismo y Estrategia Territorial.

May, Peter J. (2003): "Policy design and implementation", en B. Guy Peters and Jon Pierre (eds.), Handbook of Public Administration (Sage, London) pp. 223-233. 
Organización de Cooperación y Desarrollo Económicos y Comisión Económica para América Latina y el Caribe (2005): Evaluación del Desempeño Ambiental Chile (Santiago, Naciones Unidas, CEPAL).

Parejo Alfonso, Luciano (1998): "La ordenación del territorio y el urbanismo", en Parejo Alfonso, L.; Jiménez-Blanco, A.; Ortega Álvarez, L., Manual de Derecho Administrativo (t. II, Barcelona, Ariel).

Pérez Andrés, Antonio (1997): La planificación territorial en el Estado compuesto. La función pública de ordenación del territorio (Tesis doctoral defendida en la Facultad de Derecho de la Universidad de Sevilla).

QujJada, S. Rodrigo (1994): Diccionario Jurídico (Santiago de Chile, Editorial Jurídica Conosur).

Rajevic Mosler, Enrique (2001): "La planificación urbana en Chile", Revista de Derecho del Consejo de Defensa del Estado, No 3: pp. 81-100.

Real Academia Española de la Lengua (2012): Diccionario de la Lengua Española (Madrid, vigésima segunda edición y enmiendas incorporadas hasta 2012). Versión electrónica disponible en http://www.rae.es/diccionario-de-la-lengua-espanola/el-diccionarioen-el-brae\#sthash.7IIilvFS.dpuf.

Subsecretaría de Desarrollo Regional (2010): Plan Regional de Ordenamiento Territorial. Contenido y procedimiento (Santiago, SUBDERE).

Subsecretaria de Desarrollo Regional (2013): Guia análisis y zonificación de cuencas hidrográficas para el ordenamiento territorial (Santiago, SUBDERE).

Therivel, Riki et al. (1994): Strategic Environmental Assessment (Londres, Earthscan).

Therivel, Riki y Paridario, María Rosario (2002): The Practice of Strategic Environmental Assessment (Londres, Earthschan).

TOledo TAPIA, Fernando (1996): Ley 19.300 sobre bases generales del medio ambiente, historia fidedigna y concordancias internas (Santiago, Comisión Nacional del Medio Ambiente, primera edición).

Troncoso Tirapegui, Juan José: El reglamento pendiente de la EAE, en la columna de opinión del Diario El Pulso del martes 17 de junio de 2014. Disponible en www.pulso.cl, http://static.pulso.cl/20140616/1960065.pdf .Fecha de consulta:20 de septiembre de 2015.

Varela del Solar, Jorge Luis (2012): "Evaluación Ambiental Estratégica: instrumento sustantivo de regionalización”, Revista Actualidad Jurídica, vol. 13, № 26 : pp. 301-322.

Vargas Delgado, Iris (2006): "Las funciones de la Contraloría General de la República y la fiscalización medioambiental, Especial referencia a la función dictaminadora", Actas de las Tercera Jornadas de Derecho Ambiental : pp. 31-45.

Vergara Blanco, Alejandro (2008): Aspectos legales en la Estrategia Nacional de Gestión Integrada de Cuencas Hidrográficas (Santiago, Centro de Documentación CONAMA).

Vergara Blanco, Alejandro (2014): Crisis institucional del agua (Santiago, LegalPublishing).

Verheem, Raa y Tonk, Jamn (2000): "Strategic environmental assessment: one concept, multiple forms", Impact Assessment and Project Appraisal, vol. 18, No 3: pp. 177-182. 
Wood, Christopher y Dejeddour, Mohammed (1992): "Strategic environmental assessment: ea of policies, plans and programmes", Impact Assessment Bulletin, No 10 : pp. 3-22.

\section{NORMAS CITADAS}

Constitución Política de la República.

Ley N 19.300 (9/3/1994), sobre Bases del Medio Ambiente.

LEY $N^{\circ} 19.880$ (29/5/2003), sobre bases de los procedimientos administrativos que rigen los actos de los órganos de la Administración del Estado.

Ley N 20.417 (26/1/2010), que Crea el Ministerio, el Servicios de Evaluación Ambiental y la Superintendencia del Medio Ambiente.

Ley No 20.434 (8/4/2010), que Modifica la Ley General y Acuicultura en materia de acuicultura.

DFL Nº 458 (13/4/1976), del Ministerio de Vivienda y Urbanismo, Aprueba nueva Ley General de Urbanismo y Construcciones.

DFL $N^{\circ} 1(8 / 11 / 2005)$, del Ministerio del Interior, Fija el texto refundido, coordinado sistematizado y actualizado de la Ley $N^{\circ} 19.175$, Orgánica Constitucional sobre Gobierno y Administración Regional.

DFL N ${ }^{\circ} 1$ (26/7/2006), del Ministerio del Interior, Fija el texto refundido, coordinado y sistematizado de la Ley $\mathrm{N}^{\circ}$ 18.695, Orgánica Constitucional de Municipalidades.

DS No 40 (12/8/2013), del Ministerio del Medio Ambiente, que aprueba el Reglamento del Sistema de Evaluación de Impacto Ambiental.

DS No 32 (4/11/2015), del Ministerio del Medio Ambiente, que aprueba el Reglamento para la EAE.

\section{JURISPRUDENCIA ADMINISTRATIVA}

Dictamen $N^{\circ} 29.333$, de 1996.

Dictamen $N^{\circ} 23.897$, de 2002.

Dictamen $N^{\circ} 865$, de 2005.

Dictamen $\mathrm{N}^{\circ} 27.856$, de 2005.

Dictamen No 59.316, de 2006.

Dictamen $\mathrm{N}^{\circ} 39.348$, de 2007.

Dictamen $N^{\circ} 45.330$, de 2008.

Dictamen $\mathrm{N}^{\circ} 78.815$, de 2010.

Dictamen $\mathrm{N}^{\circ}$ 41.275, de 2011.

Dictamen $N^{\circ}$ 65.497, de 2011.

Dictamen $\mathrm{N}^{\circ} 78.248$, de 2011.

Dictamen $\mathrm{N}^{\circ} 31.287$, de 2012.

Dictamen $N^{\circ} 53.841$, de 2012.

Dictamen $N^{\circ} 70.559$, de 2012.

Dictamen $\mathrm{N}^{\circ}$ 73.497, de 2012. 
Dictamen $\mathrm{N}^{\circ} 145$, de 2013.

Dictamen Nº.271, de 2013.

Dictamen $N^{\circ} 17.486$, de 2013.

Dictamen $N^{\circ} 36.816$, de 2013.

Dictamen No 48.885, de 2013.

Dictamen $N^{\circ} 49.074$, de 2013.

Dictamen N 66.458, de 2013.

Dictamen $\mathrm{N}^{\circ} 73.730$, de 2013.

Dictamen $N^{\circ}$ 74.747, de 2013.

Dictamen $N^{\circ} 1.765$, de 2014.

Dictamen $N^{\circ} 11.429$, de 2014.

Dictamen $N^{\circ} 14.462$, de 2014.

Dictamen No30.171, de 2014.

Dictamen No 34.481, de 2014.

Dictamen N³9.390, de 2014.

Dictamen N 64.423, de 2014.

Dictamen $N^{\circ} 83.151$, de 2014.

Dictamen No 97.773, de 2014.

Dictamen No 99.760, de 2014. 